\title{
Study of Express Package Recycling Innovation Mechanism Based On Energy Conservation
}

\author{
Shijie Wang \\ School of Electrical \& Electronic Engineering, North China Electric Power University, Baoding, \\ 071003 China
}

328799219@qq.com

\begin{abstract}
With China's rapid economic development and the increasing popularity of e-commerce and online shopping, modern logistics industry booms extensively. Under this circumstance, however, discarded express packages also produced a series of garbage pollutions. This paper was based on the background of express package pollution, for the purpose of energy conservation and the harmonious relationship between human being and nature. By utilizing the methods of questionnaires and data comparison and analysis, this paper proposed the solutions of using "green taxes" and recycling mechanism innovation.
\end{abstract}

Keywords: Express package; Pollution status; Solutions.

\section{Introduction}

With the rapid development of online shopping and express delivery industry, express bring great convenience to life, but at the same time formed a large-scale garbage because of distributing and splitting. For example, the national express packaging waste in 2014 reached as many as billions and has a growing trend. Most of the courier packaging include plastic, paper products, foam filler and wood-based products. Among them, the production process of corrugated boxes is high energy consumption and high emission, which will cause water pollution and air pollution. Plastic and foam filler cannot be natural degraded, and at present, most are treated by incineration or landfill treatment, which will cause serious damage to the soil, air and water, while the paper products and wood products are wasting a lot of wood. At the same time, plasticizers, vinyl chloride and acrylic monomers used in the production of plastic do such great harm to the human body. ADC foaming agent, which serves as cushioning material, not only consumes high energy in the production, but also discharges waste water, resulting in serious water pollution. These excessive packaging wastes a lot of manpower and natural resources and poses a threat to the environment. The high cost of treatment, then indirectly affects the quality of economic growth and economic development, and brings adverse impact on economic life.

Courier packaging pollution should not be underestimated. To respond positively to the call of "energy saving and environmental protection", and to achieve energy conservation and create ecological civilization, this paper presents innovative recycling mechanism to solve this problem after investigation and analysis.

\section{Receiving express "Green Taxes"}

Green taxes are also called environmental protection tariff, green tariffs or ecological tariffs, which is a protective behavior for the pollution in international trade. And the proposal of express "green taxes" is also for punishing pollution behavior in the process of express, in order to better constrain the excessive packaging behavior of sellers and consumers in the process of delivery.

Specifically, in the collection of tax rates, tax collection standard may be specified in accordance with the courier material, size, weight and other criteria, which means the express delivery with less weight, more environmentally friendly materials, and smaller volume will be charged less "green tax". As to the objects in collecting taxes, tax rates standard is only for senders and recipients [Due to the fact that current express consumers consist most of sellers and buyers online, therefore they will be 
divided into senders and recipients. Furthermore, in order to better constrain the behavior of both sides and improve the recovery of delivery packaging, the settings of the taxes should follow the principle of assuming 50\% from both sides, which is to say the senders bear 50\% of the taxes and the recipients bear $50 \%$ of taxes, too. In terms of tax refund, for the senders, the taxes will not be returned, in order to encourage them to use easier packing and environmentally friendly packaging. But for the recipients, to encourage express packaging recycling, it stipulates: If the recipients retreat express packaging back to relevant courier packaging recycling stations, then $25 \%$ tax will be refunded. Since the tax is not too high, the refund can be of a variety of ways, such as gold accumulation of Taobao, Jingdong beans and so on.

In addition, the use of taxes and charges can be roughly divided into two categories: The first category is to hand in the state treasury. Like other tax policies, environmental tax policy is formulated by the state, so the government should finally recovers most of the taxes. After green taxes go into the state treasury, they will be arranged uniformly by the state funding, and the government can consider putting greater emphasis on the support of the environmental protection industry. The second category is to hand out to courier companies, as the rewards to couriers for doing extra work in the recovery process. The couriers play important roles in the recovery process, because they promote the conduct of recycling. The rewards should also be paid according to performance, which means couriers with more recovered packaging naturally can obtain more money, and this can also encourage the couriers to contribute more to the recovery work.

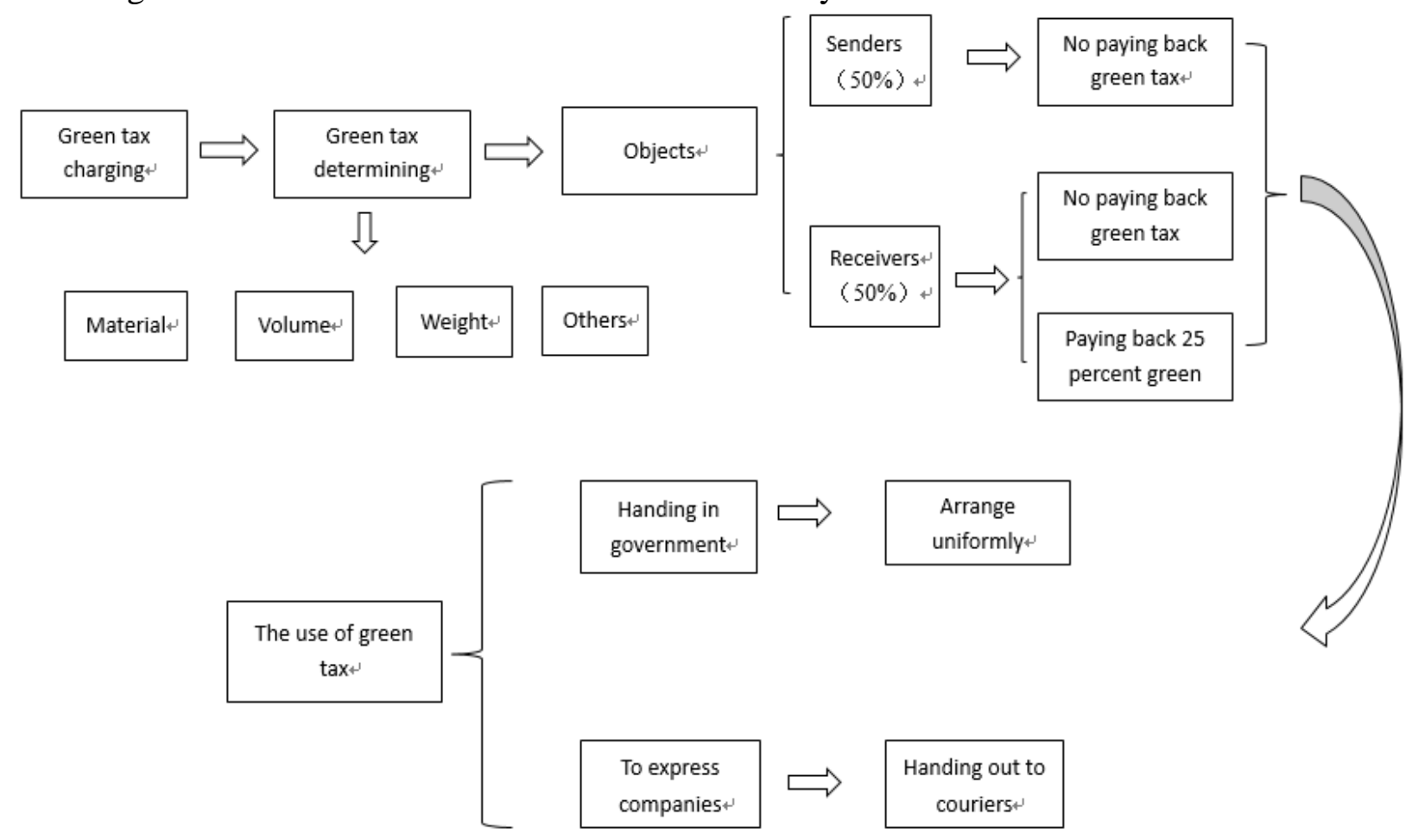

Fig. 1.Express green taxes flowchart

\section{Recycling Process Description}

Currently, there is little study of the recovering of the express garbage and the utilization of waste, both at home and abroad, but we can draw relevant lessons from other areas. Although there are significant differences in the specific practices, the guiding ideology and philosophy are almost the same. Among them, the related research practices of building industry waste recycling are more completed, which are worth learning.

Japanese government controls large-scale construction waste through laws and regulations. It developed "the norms of using recycled aggregate and recycled concrete" in 1977 and 1991, which stipulated that the construction waste generated during construction must be sent to the "recycling 
equipment" for reprocessing. French CSTB Company is Europe's leading group of "waste and construction", specially being responsible for the co-ordination "waste and construction" business in Europe. One of the company's targets is to forecast and assess of the production and collection of construction waste during the construction, improvement and demolition works, to determine the relative recovery applications to enhance the waste management hierarchy. Germany created a multi-linkage of the garbage collection mechanism, aiming at avoiding waste from businesses, citizens and the government and treating the waste in an environmentally accommodated manner.

In terms of the above summary and analysis, this paper proposed the following measures to achieve the courier industry waste recycling targets. First, courier companies can build garbage collection centers and garbage delivery point transceiver in various delivery points to separate and recycle various courier garbage. The packaging can be divided into three categories: plastic garbage, trash cartons and other trash.

Second, the government needs to play a guiding and supporting role both in policy and funding. Government needs to introduce relevant laws and regulations to support and encourage the courier garbage collection from a policy aspect. Some courier companies or sellers of the good performance can get preferential policies and institution. Government can also set aside a small portion of the funds from the finance to build recycling plants. The renewable garbage recycled from garbage collection center established by express companies can be sent to the plants to be re-created to available packaging material. For example, a carton can be mashed into a pulp carton and re-manufactured into new cardboard boxes. This can reduce the use of raw materials and save resources. Of course, renewable garbage refers to those seriously damaged packaging which cannot be directly reused. They can only be recycled and re-created to be re-used. For those poorer quality crates which can be directly used again, they can be shipped back to the local courier company headquarters by couriers and arranged uniformly by the courier company. For example, they can be sold to some local sellers using a large amount of packaging at a lower price to complete the recycling process. This can decrease their requirements of newly produced packaging. For those boxes which are relatively intact and can be used directly in the delivery process again without affecting the safety of goods during transportation, they can be left directly to the couriers, serving as the packing for the next sent. This will greatly facilitate the senders, because the senders do not need to bring their own boxes, and the couriers will offer free boxes of suitable size.

Third, for sellers, they should establish a sense of simply packaging. When the sellers send goods, they don't need to over-package the commodities for aesthetics, as long as they can ensure that goods are not damaged during transportation. Here, the online malls, such as Taobao, Jingdong and other companies, should work together with consumers. Online stores can increase one category called the degree of a package of goods in the commodity evaluation to accumulate the assessments from consumers. If the assessments are accumulated to a certain extent, they can get some money rewards, and the rewards fund from the previously mentioned environmental taxes. Monetary incentives can often achieve better results.

Fourth, we may also take such incentives for consumers. Consumers can pick up a integration card from the garbage collection center. Each time the consumers put the courier refuse to garbage collection center, they can get some points, and when the points reach a certain limit, and they can receive certain incentives. Of course, when consumers become senders, if they choose to receive a free courier package with a proper size of from the couriers, they can also earn points. The funding also comes from the green tax.

\section{Conclusion}

Based on the fact that the concept of energy-saving and emission reduction are now increasingly valued, the new express packaging recycling mechanism makes it easier for people to accept. Interest is the leverage to drive this process, so in this paper, the interests of government, consumers and sellers are measured. If this recovery mechanism can be put into practice, not only can it have a 
tremendous social benefits, but also promotes ecological civilization and makes people's homes more beautiful.

\section{References}

[1] Haiyun Xu, Qingsong Li, Lixin Zhai, Cai Jian Li. German two-track system and packaging waste disposal [J].Environmental Sanitation Engineering, 2001, 03:153-155.

[2] Liping Yu. Packaging waste treatment methods in developed countries [J].Hunan Packing, 2014, 04:82-85.

[3] Jing Song, Jinlong Chen, Jing Zhang, Chao Guan, Tianli Zhang, Xiaojun Yang. Investigation and analysis of campus waste recycling [J].New West (Theory), 2015, 02:56-57.

[4] Jianing Zhang, Fang Liu. Thinking of express packaging low-carbon design [J]. Packaging Engineering, 2014, 04:82-85.

[5] The reporter, Jianhua Gao. Why is express packaging recycling difficult [N]. Shanxi Daily, 2014-04-03C01. 